\title{
GIS-BASED WIND FARM SITE SELECTION MODEL OFFSHORE ABU DHABI EMIRATE, UAE
}

\author{
N. Saleous ${ }^{\text {a, } *, \text { S. Issa }}{ }^{\text {b }}$, J. Al Mazrouei $^{\mathrm{c}}$ \\ ${ }^{a}$ United Arab Emirates University, Geography and Urban Planning Department, Al Ain, United Arab Emirates - \\ nazmi.saleous@uaeu.ac.ae \\ ${ }^{\mathrm{b}}$ United Arab Emirates University, Geology Department, Al Ain, United Arab Emirates - salem.essa@uaeu.ac.ae \\ ${ }^{\mathrm{c}}$ United Arab Emirates University, MSc in RS/GIS Program, United Arab Emirates-201370081@uaeu.ac.ae
}

\section{Commission VI, WG VI/4}

KEY WORDS: Wind Energy, Offshore Wind Farm, UAE, GIS, Site Selection

\begin{abstract}
:
The United Arab Emirates (UAE) government has declared the increased use of alternative energy a strategic goal and has invested in identifying and developing various sources of such energy. This study aimed at assessing the viability of establishing wind farms offshore the Emirate of Abu Dhabi, UAE and to identify favourable sites for such farms using Geographic Information Systems (GIS) procedures and algorithms. Based on previous studies and on local requirements, a set of suitability criteria was developed including ocean currents, reserved areas, seabed topography, and wind speed. GIS layers were created and a weighted overlay GIS model based on the above mentioned criteria was built to identify suitable sites for hosting a new offshore wind energy farm. Results showed that most of Abu Dhabi offshore areas were unsuitable, largely due to the presence of restricted zones (marine protected areas, oil extraction platforms and oil pipelines in particular). However, some suitable sites could be identified, especially around Delma Island and North of Jabal Barakah in the Western Region. The environmental impact of potential wind farm locations and associated cables on the marine ecology was examined to ensure minimal disturbance to marine life. Further research is needed to specify wind mills characteristics that suit the study area especially with the presence of heavy traffic due to many oil production and shipping activities in the Arabian Gulf most of the year.
\end{abstract}

\section{INTRODUCTION}

The growing world population, the fast depletion of fossil fuel reserves and the documented climatic effects of fossil fuel burning have prompted world governments to pursue renewable energy alternative (El Chaar and Lamont 2010). The United Arab Emirates (UAE) is no exception. Based on 2009 figures, 98\% of electricity in the country is generated from natural gas power plants (Mondal et al 2014). With an unprecedented rate of economic growth and abnormal population growth, the increased demand for electricity lead to increases in $\mathrm{CO}^{2}$ emissions. (Kazim 2010). UAE government has set a goal to reduce emission rates and seek alternative sources of energy.

Wind power is readily available and has been used throughout history to help accomplish mechanical task such as water pumping. The development of turbines that convert wind energy into electrical energy put wind in a good position as a source of alternative renewable energy. Having wind machines with 15-20 years lifespan that can be implemented at sufficient wind sites, makes wind energy competitive with other renewable energy systems for electricity generation. (Ammari et al 2015). Furthermore, wind has become one of the fastest growing renewable energy sources for power generation and has become more competitive with conventional energy sources in recent years. (Chandel et al 2014).

Wind farms are often planned offshore where wind conditions are favorable and the visual impact is less important (Punt et al 2009). These farms, in addition to being economically viable, should have an insignificant impact on the local environment in terms of visual and noise intrusion, electromagnetic interference and possible wildlife collisions (Baban and Parry 2001). The most important factor in selecting a new site for offshore wind farm is the availability of adequate wind resources (Kim et al 2013). Water depth and soil conditions determine the type of foundation needed for the wind farm and have a significant impact on its economic feasibility (Kim et al 2013). Existing and proven stationary foundations can be used in depths up to $50 \mathrm{~m}$. Beyond that depth, less developed floating foundations are needed. Additionally, offshore wind farms should be sited to minimize their effect on ecology away from bird habitat and migration paths, and away from fish habitat (Mekonnen and Gorsevski 2015).

This study aims to assess the feasibility of establishing wind farms offshore the Emirate of Abu Dhabi, UAE and to identify favourable sites for such farms using a Geographic Information System (GIS).

\section{STUDY AREA}

\subsection{Location and characteristics}

The UAE is located in the south-eastern part of the Arabian Peninsula. It is bordered by the Arabian Sea and Oman in the east, Saudi Arabia in the south and west and the Arabian Gulf in the north. The study area, shown in figure 1, covers the waters of the Emirate of Abu Dhabi in the Arabian Gulf where extensive shallow regions, less than $20 \mathrm{~m}$ deep, are found along the coast of the Emirate.

\footnotetext{
* Corresponding author
} 


\subsection{Winds in UAE}

Wind speed in the UAE is generally below $10 \mathrm{~m} / \mathrm{s}$ for most of the year. In the winter, stronger winds exceeding $20 \mathrm{~m} / \mathrm{s}$ and sustaining for about 4-days occur almost in cyclic fashion from the end of January. The weaker winds mostly flow from the east and show diurnal oscillation. All strong winds, regionally known as 'shamal', come from the northwest. The summer winds are much weaker than in the winter and mostly blow from northwest direction. Their speed rarely exceeds $10 \mathrm{~m} / \mathrm{s}$ and stronger winds do not sustain for long duration. (Elshorbagy et al 2013; Ouarda et al. 2015).

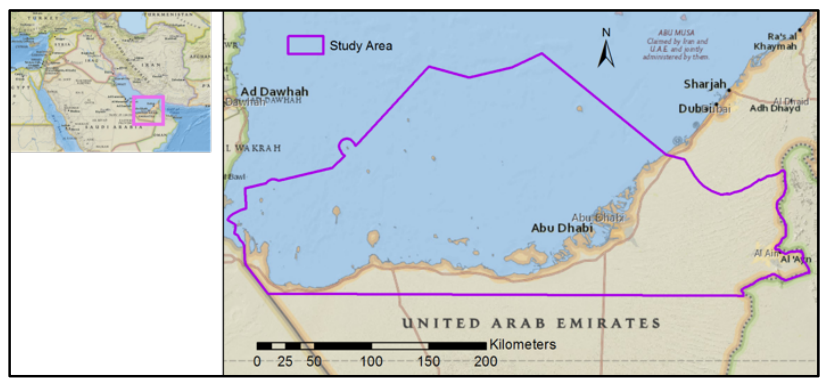

Figure 1: Study area

The map of UAE mean wind speed at $50 \mathrm{~m}$ extracted from the National Renewable Energy Laboratory shown in figure 2, indicates that areas offshore the Emirate of Abu Dhabi experience wind speeds in the range of 5-6 m/s, exceeding the wind speed threshold for power generation (Baban and Parry 2001), indicating good potentiality for offshore AD to construct feasible wind farms.

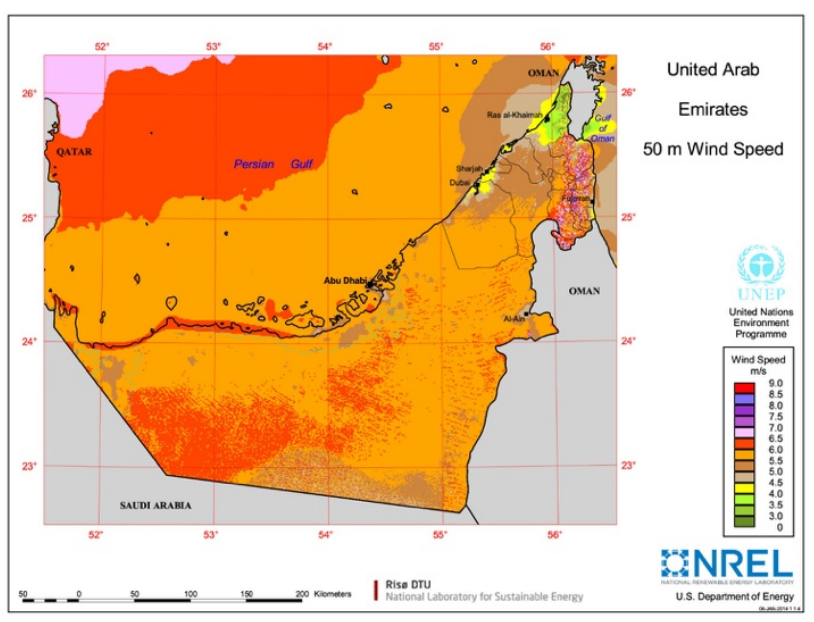

Figure 2: Mean wind speed at $50 \mathrm{~m}$ over UAE (source: NREL)

\subsection{Oil and gas fields}

The discovery and production of oil in the Emirate of Abu Dhabi marks a turning point in its economy since the sixties of last century. The oil industry is a major source of wealth for the emirate and plays a strategic role in the Union. As seen in figure 3 showing oil and gas fields in UAE, Abu Dhabi holds a significant number of these fields in its waters (Watts 2013). These fields' protected areas need to be excluded from the list of potential sites for wind energy farms.

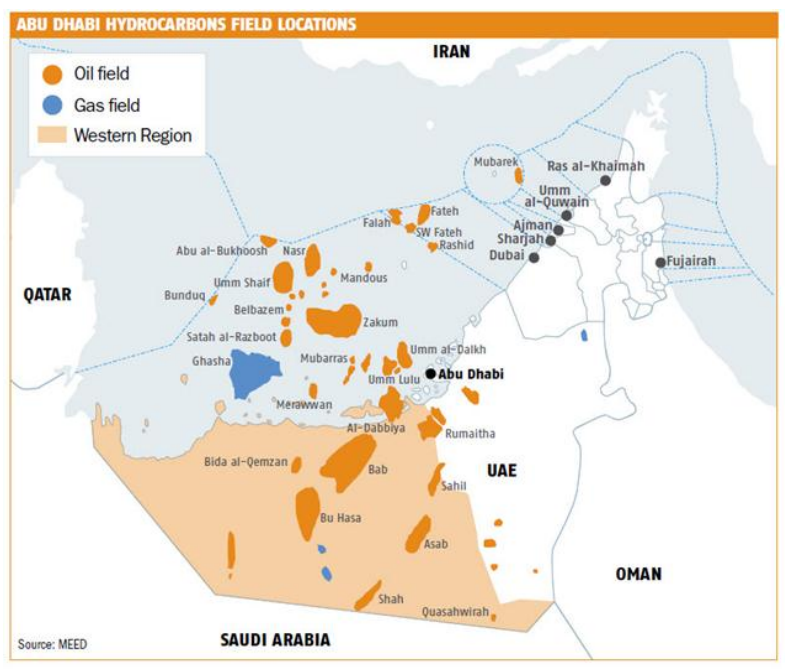

Figure 3: Oil and gas fields in UAE (source: Watts 2013)

\subsection{Marine conservation areas}

Many of the species that enrich Abu Dhabi Emirate's natural heritage have become endangered due to many factors including pressure from expanding population, increasing demand for food, and industrial and urban encroachments. The Environment Agency of Abu Dhabi (EAD) has classified specific locations as Marine Protected Areas (MPAs) or Terrestrial Protected Areas (TPAs) as shown in figure 4. There are six main protected areas in Abu Dhabi, two of which are marine: Marawah Marine Biosphere Reserve and Al Yasat Marine Protected Area. These areas are considered restricted and cannot be used to host wind energy farms.

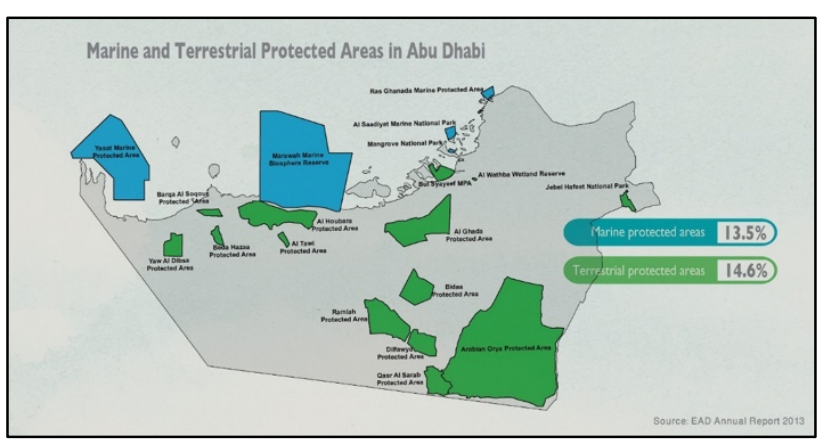

Figure 4: Map of Marine and Terrestrial Protected Areas of Abu Dhabi, (source: EAD 2013)

\section{METHODOLOGY}

This study adopts a GIS-based methodology to identify areas suitable for building offshore wind farms. The selection process is performed in two stages: an area exclusion stage and an area ranking stage. The former identifies all areas where wind farms cannot be built based on environmental and economic criteria. These areas are excluded from subsequent processing. The second stage ranks remaining areas based on average wind speed and water depth. It identifies unsuitable, moderately suitable and suitable areas.

\subsection{Selection Criteria}

The criteria used to determine suitable locations for wind farms are divided into two categories according to their role. The first category yields a binary decision and is used in determining the 
excluded area mask. The second category is used to compute a suitability score to determine different area suitability levels.

The set of of criteria for the first category is summarized in table 1 along with the conditions used to warrant the exclusion from potential suitable sites. These criteria include environmental parameters to exclude areas listed by the Environmental Agency of Abu Dhabi (EAD), safety parameters mainly related to traffic in the gulf and economic parameters primarily related to the country's oil and gas industry.

\begin{tabular}{|l|l|}
\hline Parameter & $\begin{array}{l}\text { Unsuitability } \\
\text { Condition }\end{array}$ \\
\hline Water/Land mask & Land \\
\hline Submarine cables & Within $250 \mathrm{~m}$ \\
\hline Oil and gas wells & Within $250 \mathrm{~m}$ \\
\hline Oil and gas pipelines & Within $250 \mathrm{~m}$ \\
\hline Bird conservation sites & Inside \\
\hline Environmentally protected areas & Inside \\
\hline Maritime navigation corridor & Inside \\
\hline
\end{tabular}

Table 1: Criteria used to exclude areas from the selection process

The set of criteria for the second category is summarized in table 2. It includes wind speed and water depth. The suitability conditions adopted in the study are based on published literature. Areas where wind speed are below $4.5 \mathrm{~m} / \mathrm{s}$ are not favourable for wind energy and deemed unsuitable (Latinopoulos and Kechagia 2015). Areas where wind speeds are above $5 \mathrm{~m} / \mathrm{s}$ can be considered suitable (Baban and Parry 2001). The water depth has an economic implication on the choice wind farm site as it affects its installation cost (Higgins and Foley 2014; Yamaguchi and Ishihara 2014). On the other hand, installation in shallow water can affect the benthic ecology (Mee 2006). The optimum choice of water depth is hence a trade-off these constraints.

\begin{tabular}{|l|l|}
\hline Parameter & Suitability Condition \\
\hline Wind speed & $<4.5 \mathrm{~m} / \mathrm{s}:$ unsuitable \\
& $4.5-5.4 \mathrm{~m} / \mathrm{s}:$ moderately suitable \\
& $>5.4 \mathrm{~m} / \mathrm{s}:$ suitable \\
\hline Water & $0-10 \mathrm{~m}:$ moderately suitable \\
depth & $10-20 \mathrm{~m}:$ suitable \\
& $>20 \mathrm{~m}:$ unsuitable \\
\hline
\end{tabular}

Table 2: Criteria used to rank non-excluded areas

\subsection{Data sets and geodatabase}

Data needed for this study are collected from different sources in different formats and characteristics. They are pre-processed into the same spatial reference system and stored in a geodatabase for use in GIS. Table 3 summarizes the data sets collected and main characteristics.

\begin{tabular}{|l|l|l|l|}
\hline parameter & layer & $\begin{array}{l}\text { Geometry } \\
\text { type }\end{array}$ & Date \\
\hline $\begin{array}{l}\text { Land/water } \\
\text { mask }\end{array}$ & AD_Land & Polygon & 2012 \\
\hline $\begin{array}{l}\text { Submarine } \\
\text { Cables }\end{array}$ & Water_lines & Line & 2012 \\
\hline $\begin{array}{l}\text { Oil and Gas } \\
\text { Wells }\end{array}$ & Pump_rig & point & 2015 \\
\hline $\begin{array}{l}\text { Oil and Gas } \\
\text { pipes }\end{array}$ & Oil_lines & line & 2012 \\
\hline $\begin{array}{l}\text { Bird } \\
\text { conservation } \\
\text { sites }\end{array}$ & Bird_areas & polygon & 2009 \\
\hline
\end{tabular}

\begin{tabular}{|l|l|l|l|}
\hline $\begin{array}{l}\text { Environmentally } \\
\text { protected areas }\end{array}$ & Protected_areas & polygon & 2009 \\
\hline $\begin{array}{l}\text { Maritime } \\
\text { navigation } \\
\text { corridor }\end{array}$ & Navigation_routes & polygon & 2012 \\
\hline $\begin{array}{l}\text { Wind speed at } \\
50 \mathrm{~m}\end{array}$ & Wind_speed & raster & 2015 \\
\hline Water depth & Bathymetry & raster & 2010 \\
\hline
\end{tabular}

Table 3: Data sets used in the study

\subsection{Creation of exclusion mask}

The first stage in the model requires the creation of an exclusion mask defined by the set of constraints listed in table 1 . The mask is created in GIS according to the diagram in figure 5.

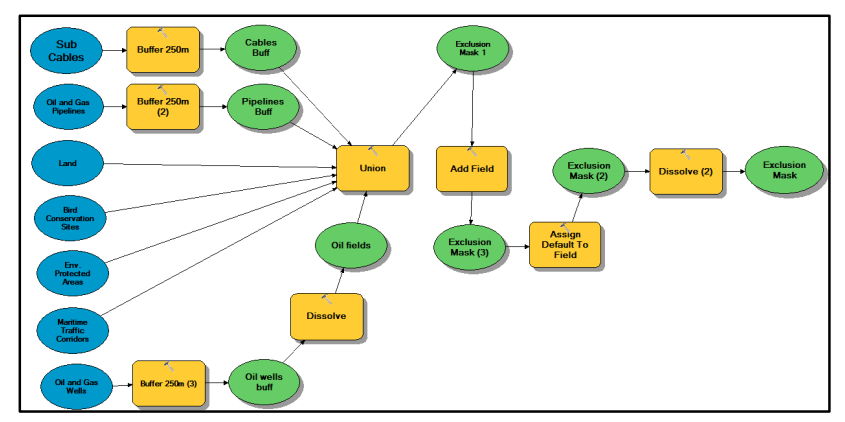

Figure 5: diagram of area exclusion model

\subsection{Creation of suitability maps}

Areas that are not excluded by the first stage of the model are candidates for wind farms. Their suitability is evaluated using the criteria listed in table 2. The approach adopted in this study is based on a weighted sum overlay whose inputs are derived from the wind speed and water depth layers. For the weighted sum model to run properly, the two inputs need to be reclassified and ranked using a similar scheme. To be consistent with the set of criteria defined in table 2 , we start by reclassifying and ranking the wind speed and bathymetry raster input images according to table 4. Reclassified images from both input will have values between 1 and 3 .

\begin{tabular}{|l|l|l|}
\hline Wind speed (v) & Bathymetry $(\mathrm{d})$ & ranking \\
\hline $\mathrm{v}<4.5 \mathrm{~m} / \mathrm{s}$ & $\mathrm{d}>20 \mathrm{~m}$ & 1 \\
\hline $4.5<=\mathrm{v}<=5.4 \mathrm{~m} / \mathrm{s}$ & $0<\mathrm{d}<10 \mathrm{~m}$ & 2 \\
\hline $\mathrm{v}>5.4 \mathrm{~m} / \mathrm{s}$ & $10<=\mathrm{d}<=20 \mathrm{~m}$ & 3 \\
\hline
\end{tabular}

Table 4: ranking of wind speed and bathymetry inputs

The suitability of a location (S) is then calculated from the reclassified inputs using the weighted sum defined in formula (1).

$$
\mathrm{S}=\mathrm{w}_{\text {wind }} * \text { ranked wind speed }+\mathrm{w}_{\mathrm{depth}} * \text { ranked water depth }
$$

where $\mathrm{w}_{\text {wind }}$ is the weight given to the wind speed criterion and $\mathrm{w}_{\mathrm{depth}}$ is that given to the water depth criterion.

Given the higher importance of wind in the suitability of a location for wind farming, we assign a value of 2 to $\mathrm{w}_{\text {wind }}$ and 1 to $\mathrm{W}_{\text {depth. }}$. The calculated suitability $(\mathrm{S})$ can then take values between 3 and 9 as illustrated in table 5 . 


\begin{tabular}{|l|l|l||l|l|l||l|l|l|}
\hline v & d & S & v & d & S & v & d & S \\
\hline 1 & 1 & 3 & 2 & 1 & 5 & 3 & 1 & 7 \\
\hline 1 & 2 & 4 & 2 & 2 & 6 & 3 & 2 & 8 \\
\hline 1 & 3 & 5 & 2 & 3 & 7 & 3 & 3 & 9 \\
\hline
\end{tabular}

Table 5: Suitability values as function of ranked wind speed (v) and ranked water depth $(\mathrm{d})$

The suitability is then reclassified and ranked between 1 and 3 as per table 6.

\begin{tabular}{|l|l|l|}
\hline Suitability (S) & Ranking & Condition \\
\hline $3-5$ & 1 & Unsuitable \\
\hline $6-7$ & 2 & Moderately suitable \\
\hline $8-9$ & 3 & Suitable \\
\hline
\end{tabular}

Table 6: Ranking of the Suitability results

\section{RESULTS AND DISCUSSION}

The approach presented in section 3 is applied to create the suitability map for potential locations of wind farm offshore the Emirate of Abu Dhabi. As detailed earlier, the model is run in two stages: creation of excluded areas mask and creation of suitability map.

\subsection{Exclusion mask}

The model described in figure 5 is used to create the excluded areas mask shown in figure 6 . Areas painted in red are not suitable and will not be considered in the selection process. Environmentally protected areas represent the bulk of the constrained offshore areas followed by oil and gas related locations.

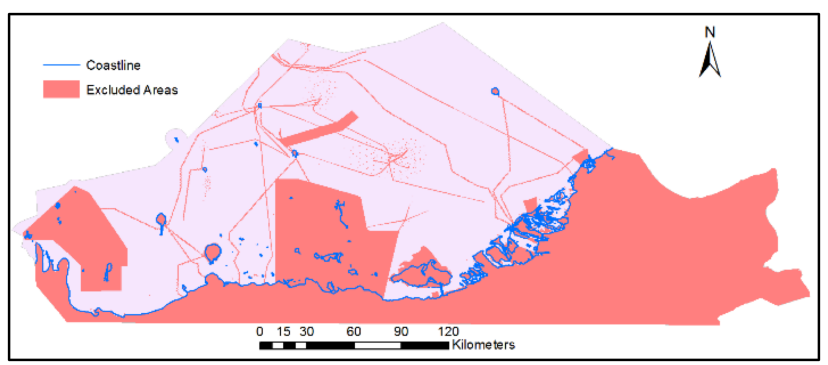

Figure 6: Exclusion mask

\subsection{Reclassified wind speed map}

Wind speed is the primary factor affecting the suitability of a location for wind energy production. As discussed in the previous section, annual wind speed is reclassified producing a ranking of 1-3 for use in the suitability model. The result of this reclassification is shown in figure 7.

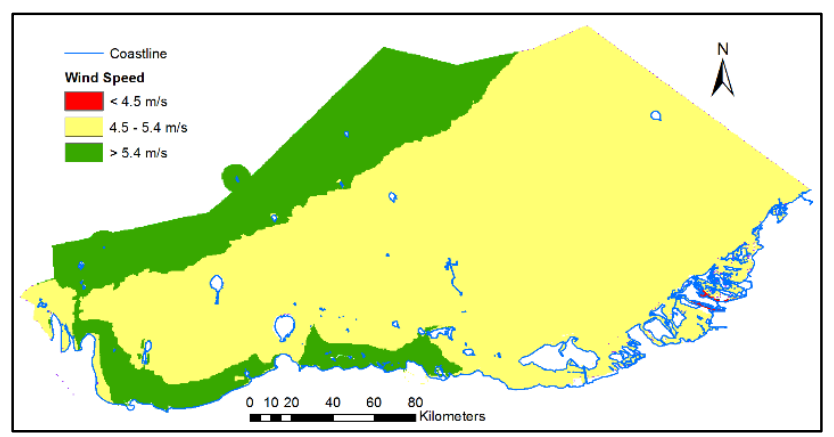

Figure 7: Reclassified annual wind speed
It is shown from figure 7 that winds with average speed of $4.5-$ $5.4 \mathrm{~m} / \mathrm{s}$ dominates the major part of Abu Dhabi's offshore areas.

\subsection{Reclassified water depth map}

Water depth is an economically important factor affecting the suitability of wind farm sites. To serve as input for the suitability model, it needs to be reclassified and ranked between 1 and 3 . Figure 8 shows the reclassified water depth in the study area.

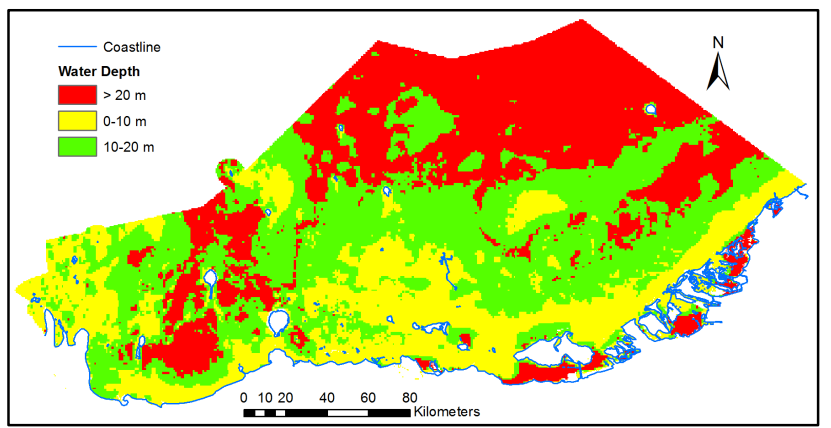

Figure 8: Reclassified water depth

\subsection{Suitability map}

The suitability model described in section 3.4 is run using the reclassified wind speed and bathymetry inputs to create the suitability map shown in figure 9. It indicates that only a small fraction of offshore Abu Dhabi Emirate is suitable for wind energy. A substantial part of that area is considered moderately suitable. However, some suitable areas are close to mainland and to inhabited islands, such as Delma Island, and can be considered for wind farms to feed these areas.

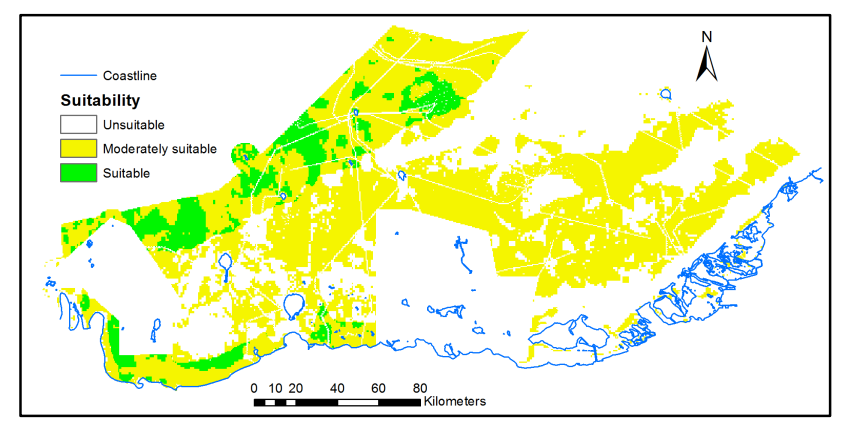

Figure 9: Suitability Map

\subsection{Environmental Impact}

Coral reefs and sea grass/macro-algal beds are two important ecological habitats in Abu Dhabi waters. Sea grass and macroalgal beds as nursery and feeding grounds for many marine species. While coral reefs house a large number of marine species. Figure 10 depicts the locations of sea grass/macro-algal beds and coral reefs along with wind farm suitability map. The figure shows that most of the sea grass is distributed along the coastline and in protected areas in zones that are unsuitable for wind energy. Similarly, coral reefs are found away from areas suitable for building wind farms. Hence, these two important ecological systems are not expected to be disturbed by potential wind farms in Abu Dhabi waters. 


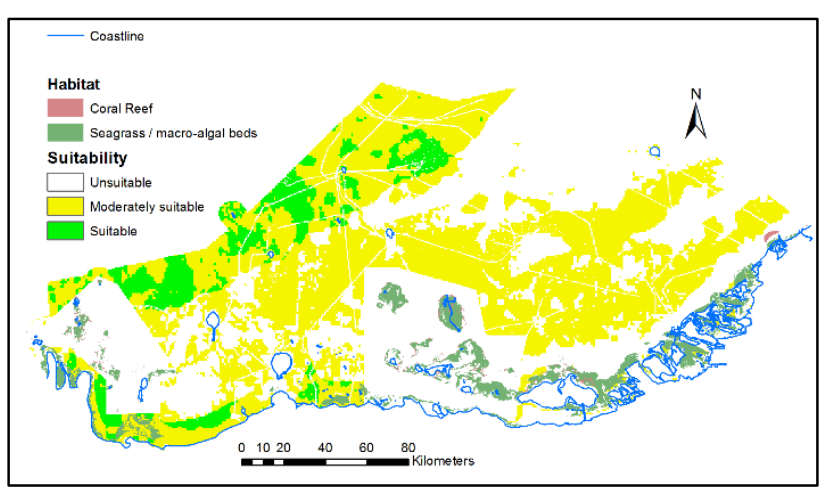

Figure 9: Suitability map and ecological habitat

\section{CONCLUSION}

The objectives of this study were to assess the viability of establishing wind farms offshore the Emirate of Abu Dhabi, UAE and to identify favourable sites for such farms through mapping of the offshore obstacles and prohibited areas and to identify suitable locations for eventual wind farms. GIS was efficient in assembling and evaluating layers of spatial variables that were incorporated into a multi-criteria model. The model was consisted of two stages: an area exclusion stage and an area suitability ranking stage. Once the excluded areas were identified, a weighted overlay model was run to classify the remaining suitable areas and create the final suitability map. The results identified suitable, less suitable and unsuitable places for wind farms to be built in offshore of Abu Dhabi Emirate. The most suitable areas were identified around Delma Island and North of Jabal Barakh in the Western Region.

Finally, the GIS-based model was very successful in identifying potential sites for eventual wind farms construction. Although, most of the suitable areas were found far away from the main land making it costly to transfer generated electricity to areas of high demand. It is worth noting that first, some suitable areas are close to inhabited islands, such as Delma Island, and can be considered for wind farms to feed these islands. Secondly, there are those close areas to the western region shoreline (extending more than $50 \mathrm{~km}$ !!) which can serve as potential sites for wind farm plantation and power generation feeding the mainland.

\section{REFERENCES}

Ammari, H., Al-Rwashdeh, S., Al-Najideen,, M., 2015. Evaluation of wind energy potential and electricity generation at five locations in Jordan. Sustainable Cities and Society. 15(2015) 135-143.

Baban, S., Parry, T., 2001. Developing and applying a GISassisted approach to locating wind farms in the UK. Renewable Energy. 24 (2001) 59-71.

Chandel, S., Ramasamy, P., Murthy, K., 2014. Wind power potential assessment of 12 locations in western Himalayan region of India. Renewable and Sustainable Energy Reviews. 39 (2014) 530-545.

EAD, 2013, Environment Agency Abu Dhabi 2013 Annual Report,

https://www.ead.ae/Publications/Annual\%20Report\%202013/E

AD-Annual-report-ENG-2013-amended-2.pdf
El Chaar, L., Lamont, L., 2010. Global solar radiation: Multiple on-site assessments in Abu Dhabi, UAE. Renewable Energy. 35 (2010) 1596-1601.

Elshorbagy, W., Azam, M., Elhakeem, A. 2013. TemperatureSalinity modeling for Ruwais coastal area in United Arab Emiarates. Marine Pollution Bulletin. 73 (2013) 170 - 182

Higgins, P., Foley, A., 2014. The key technology and development of offshore wind farm in China. Renewable and Sustainable Energy Reviews 34(2014) 453-462.

Kazim, A., 2015. Strategy for a sustainable development in the UAE through hydrogen energy. Renewable Energy. 35 (2010) 2257-2269.

Kim, J., Oh, K., Kang,, K., Lee,, J 2015. Site selection of offshore wind farms around the Korean Peninsula through economic evaluation. Renewable Energy. 54(2013) 189-195.

Latinopoulos, D.; Kechagia, K., 2015. A GIS-Based MultiCriteria Evaluation for Wind Farm Site Selection: A Regional Scale Application in Greece. Renewable Energy, 78, 550-560.

Mekonnen, A., Gorsevski, P., 2015. A web-based participatory GIS (PGIS) for offshore wind farm suitability within Lake Erie, Ohio. Renewable and Sustainable Energy Reviews. 41 (2015) 162-177.

Mee, L 2006. Complementary Benefits of Alternative Energy: Suitability of Offshore Wind Farms as Aquaculture Sites. Inshore Fisheries and Aquaculture Technology, Innovation and Development. SEAFISH-Project Ref: 10517. University of Plymouth.

Mondal, M., Kennedy, S., Mezhar, T. 2014. Long- term optimization of United Arab Emirates Energy future: Policy implications. Applied Energy. 114 (2014) 466 - 474.

NREL, United Arab Emirates 50 Wind Speed, http://www.nrel.gov/wind/images/map_united_arab_emirates_s peed.jpg

Ouarda, T., Charron, C., Shin, J., Marpu, P Al-Mandoos, A., AlTamimi, M., Ghedira, H.,AlHosary, T. 2015. Probability distributions of wind speed in the UAE. Energy Conversion and Management. 93 (2015) 414 - 434.

Punt, M., Groeneveld, R., Ierland, E. Stel, J., 2009. Spatial planning of offshore wind farms: A windfall to marine environmental protection. Ecological Economics. 69(2009) 93103.

Watts, M., 2013, Ruwais flourishes on energy schemes, MEED, 20 May 2013, http://www.meed.com/sectors/government/ruwais-flourisheson-energy-schemes/3178678.article

Yamaguchi, A., Ishihara, T., 2014.Assessment of offshore wind energy potential using mesoscale model and geographic information system. Renewable Energy Reviews 69 (2014) 506515 . 